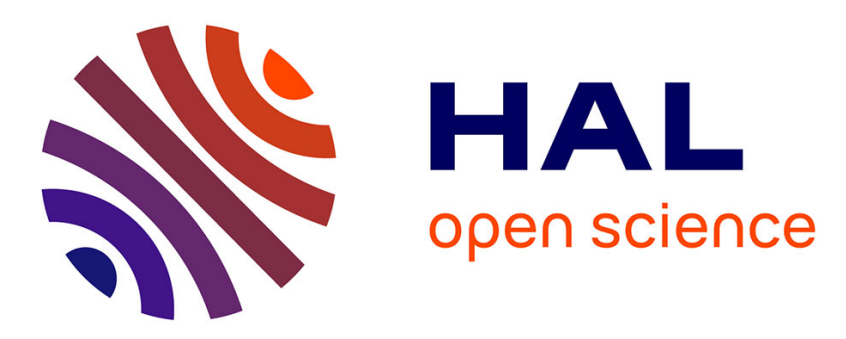

\title{
Design and Analysis of a Magnetically Geared Induction Machine
}

Badr-El-Boudour Bidouche, Thierry Lubin, Smail Mezani

\section{To cite this version:}

Badr-El-Boudour Bidouche, Thierry Lubin, Smail Mezani. Design and Analysis of a Magnetically Geared Induction Machine. 13th International Conference on Electrical Machines (ICEM), Sep 2018, Alexandroupoli, Greece. pp.629-634, 10.1109/ICELMACH.2018.8507009 . hal-01910618

\section{HAL Id: hal-01910618 https://hal.science/hal-01910618}

Submitted on 1 Nov 2018

HAL is a multi-disciplinary open access archive for the deposit and dissemination of scientific research documents, whether they are published or not. The documents may come from teaching and research institutions in France or abroad, or from public or private research centers.
L'archive ouverte pluridisciplinaire HAL, est destinée au dépôt et à la diffusion de documents scientifiques de niveau recherche, publiés ou non, émanant des établissements d'enseignement et de recherche français ou étrangers, des laboratoires publics ou privés. 


\title{
Design and Analysis of a Magnetically Geared Induction Machine
}

\author{
B. Bidouche, T. Lubin, S. Mezani
}

\begin{abstract}
This paper describes the electromagnetic and thermal design of a magnetically geared induction motor (MaGIM). The device consists of a wound-rotor induction machine artfully coupled to a magnetic gear to achieve a high torque density low speed drive system. The aim is to replace the conventional system which combines a high-speed induction motor and a mechanical gear as to improve performance and reliability.
\end{abstract}

Index Terms-Induction motor, magnetic gear, finite elements, analytical model.

\section{INTRODUCTION}

$\mathrm{T}$ he idea of a magnetic gear with permanent magnets started in 1940 when Faus patented an original magnetic gear topology [1]. Then more works have been done to achieve higher torque density. In the last decade, high performance magnetic gears have been proposed with several ways of permanent magnets arrangements [2], [3], [4], [5]. Magnetic gears have also been associated to PM synchronous machines to achieve a high torque density lowspeed drive system [6]-[7].

Despite these recent advance, there are numbers of industrial applications where it is well suited to employ an induction motor which present the advantage of self-starting when connected to the mains. Hence, a new concept called magnetically geared induction machine (MaGIM) was introduced in [8]. It associates an induction machine with a magnetic gear to achieve a high-torque/low-speed drive system with extended torque transmission capabilities. The aim is to improve the reliability and the performances of the traditional system associating a high-speed induction machine (IM) with a mechanical gearbox which exhibit mechanical problems and requires lubrication and maintenance.

We propose to study a wound rotor induction motor drive integrating a magnetic gear, which constitutes the MaGIM, the machine being supplied directly via the mains. We present in this paper the design of a $1 \mathrm{~kW}-45 \mathrm{rpm}$ MaGIM operating on the $400 \mathrm{~V} / 50 \mathrm{~Hz}$ network. We use for this purpose analytical and numerical computation tools to predict the electromagnetic and thermal performances of the

B. Bidouche, T. Lubin and S. Mezani are with Groupe de Recherche en Energie Electrique de Nancy (GREEN), Université de Lorraine - Faculté des Sciences et Technologies, BP 70239, 54506, Vandoeuvre-lès-Nancy, France (e-mail: badr-el-boudour.bidouche@univ-lorraine.fr, thierry.lubin@univ-lorraine.fr, smail.mezani@univ-lorraine.fr). device.

This paper is divided into three further sections, where Section II deals with a basic description of the Magnetically Geared Induction Machine. Next, in Section III, the development of a design procedure of the MaGIM is described. In Section IV, the performances of the machine are presented and, finally, a conclusion is given in Section V.

\section{PRINCIPLE OF OPERATION OF THE MAGIM}

As shown in Fig. 1, the studied system consists of a magnetic gear coupled to a reverse type induction motor having an inner stator and an outer rotor. The motor represents the internal part of the MaGIM while the magnetic gear represents the external part. The high-speed rotor is the common part of the motor and the magnetic gear. The conventional magnetic gear involves two rotors and a fixed armature.

The inner high-speed rotor has $\mathrm{p}_{\mathrm{i}}$ pole-pairs radially magnetized permanent magnets. The low speed rotor consists of $\mathrm{P}_{\mathrm{s}}$ ferromagnetic pole-pieces and the stationary outer armature has $\mathrm{p}_{\mathrm{o}}$ pole-pairs radially magnetized permanent magnets.

The principle of operation of the magnetic gear is based on the modulation of the magnetic field created by the $\mathrm{p}_{\mathrm{i}} \mathrm{PM}$ pole-pairs by the Ps ferromagnetic pole pieces.

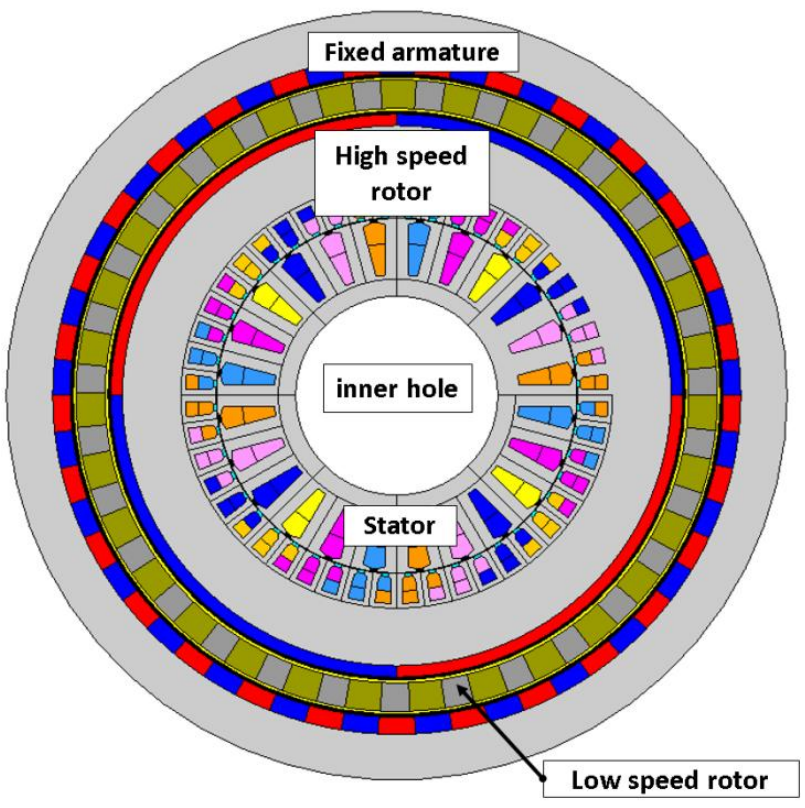

Fig. 1. 2D view of the MaGIM 
The obtained field interacts with the $\mathrm{p}_{\mathrm{o}}$ PM pole-pairs of the external armature to transmit torque to the low-speed load. The combination $\mathrm{p}_{\mathrm{o}}=\mathrm{Ps}-\mathrm{p}_{\mathrm{i}}$ results in the highest torque transmission capability of the gear [2].

The wound rotor induction motor has p pole-pairs threephase windings in the stator and the rotor armatures. This wound rotor configuration leads to a high starting torque obtained by adding resistances in series with the rotor winding. Indeed, we are looking here for a MaGIM system directly supplied via the mains for fixed speed application requiring high starting torque. The electromagnetic torque production in the IM moves the high-speed rotor at a mechanical speed $\omega_{\mathrm{i}}$. The external armature being held stationary, the torque is transmitted to the low-speed load via the pole-pieces. This torque corresponds to the one imposed by the load at a speed $\omega_{\mathrm{s}}$. It is important to note that the net average torque on the high-speed rotor (motor + magnetic gear) is equal to zero. The speeds $\omega_{\mathrm{i}}$ and $\omega_{\mathrm{s}}$ are related by [2]:

$$
\omega_{i}=\frac{P_{s}}{P_{s}-p_{o}} \omega_{s}
$$

Thus, the resulting gear ratio $\mathrm{Gr}$ is:

$$
G_{r}=\frac{P_{s}}{p_{i}}
$$

\section{DESIGN PROCEDURE OF THE MAGIM}

The design of the MaGIM is complex owing the large number of geometric and physical parameters to be considered. Indeed, there are many electromagnetic interactions between the different parts of the device, which makes it difficult to do a design with a simple sizing procedure. Furthermore, the thermal aspects are important, so a simplified thermal model is also developed to achieve a more precise design of MaGIM.

\section{A. Electromagnetic sizing of MaGIM}

The design process of the MaGIM requires the analysis of an asynchronous machine and a synchronous system (the magnetic gear). Here, we choose to study the two subsystems separately.

To achieve the electromagnetic sizing of MaGIM, we have used analytical like models for preliminary computations and finite elements to get more precise results.

- The machine air-gap diameter and active length have been firstly calculated using the electrical and magnetic loading concept together with past experience from machine manufacturers [10]. The heating factor (the product of the electric loading and the current density) has been set to a maximum value of $1000 \mathrm{~A}^{2} / \mathrm{mm}^{2} . \mathrm{cm}$ which leads to minimum cooling requirements for the machine. Then, after choosing the number of slots, one can determine the dimensions of the teeth, the back-iron, the slots and the number of turns per phase. A static linear FE computation has then been used to compute the equivalent circuit parameters of the IM from which all the machine performances are determined. Finally, non-linear transient FE computation allows a more precise calculation of the IM.

- The magnetic gear sizing uses a 2D analytical model based on the sub-domain technique [12]. Then, non-linear FE computation allows a more precise calculation of the gear performances.

Many simulations are needed to achieve a good compromise between the optimal performances of the machine and the gear sides. In the final stage, finite element analyses are carried out to consider the overall system.

We seek to design the most compact device (high torque density of the gear) with the best possible energetic performances (IM with high efficiency, high power factor...). We need then to make a compromise between the performances of the induction motor and the magnetic gear.

The load torque is exerted on the pole-pieces. For a MaGIM rated at $1 \mathrm{~kW}-45 \mathrm{rpm}$, the torque on the pole pieces is about $210 \mathrm{Nm}$. In our study, the design is done for a torque of $350 \mathrm{Nm}$ as to consider a safety margin. This margin includes 3D effects not taken into account in the 2D computation models but also to allow for any transient operation which requires torque values larger than the rated one (starting, over-load...).

For a $1 \mathrm{~kW}$ IM, the slip s is usually around 0.06 to 0.1 . Hence for $\mathrm{s}=0.1$ and a supply frequency of $50 \mathrm{~Hz}$, the gear ratio is $\mathrm{Gr}=60,30,20,15,12,10$ for $\mathrm{p}=1,2,3,4,5,6$ respectively. Induction motors have better performances for low $\mathrm{p}$ values [10] while the magnetic gear has its higher torque density for a gear ratio $\mathrm{Gr}$ ranging from 5 to 8 [11]. Then, the compromise adopted here to achieve acceptable energetic performances and compactness consists of choosing $\mathrm{p}=4$ for the IM. For the magnetic gear, we have adopted the combination $\mathrm{p}_{\mathrm{i}}=2, \mathrm{p}_{\mathrm{o}}=29, \mathrm{P}_{\mathrm{s}}=31$ which leads to a gear ratio $\mathrm{Gr}=15.5$ and minimal torque ripples [9]. This choice is also made to get reasonable dimensions of the pole-pieces as to insure their mechanical integrity while transmitting the torque.

The electromagnetic design led to the active dimensions of the MaGIM indicated in Table 1. With these dimensions, the gear exhibits a pull-out torque exerted on the pole-pieces of $350 \mathrm{Nm}$. The rated torque of the IM is equal to $14 \mathrm{Nm}$ obtained for a slip value of 0.08 .

\section{B. $\quad$ Thermal model of MaGIM}

A simplified steady state thermal network of the MaGIM has been constructed to determine the temperature distribution in the active parts. A radial heat flux is considered except for the slots for which the ortho-radial heat flux to the teeth is accounted for. The model is based on lumped parameters which involve the computation of thermal resistances [13], [14], [15]. In the solid parts, conductive thermal resistances are calculated from the 
thermal conductivities and the dimensions. Note that bulk thermal conductivities are used in the slots.

TABLE 1

MAIN GEOMETRICAL PARAMETERS OF MAGIM

\begin{tabular}{l|l}
\hline \multicolumn{1}{c}{ Magnetic gear side } \\
\hline Inner rotor pole-pairs $\mathrm{p}_{\mathrm{i}}$ & 2 \\
\hline Stationary armature poles-pairs $\mathrm{p}_{\mathrm{o}}$ & 29 \\
\hline Number of pole-pieces $\mathrm{P}_{\mathrm{s}}$ & 31 \\
\hline Gear ratio $\mathrm{G}_{\mathrm{r}}$ & 15.5 \\
\hline Airgap (inner and outer rotor sides) & $2 \mathrm{~mm}$ \\
\hline Remanence of PMs $\mathrm{B}_{\mathrm{r}}(\mathrm{NdFeB})$ & $1.2 \mathrm{~T}$ \\
\hline External radius & $131 \mathrm{~mm}$ \\
\hline Inner rotor radius $\quad$ Induction machine side & $80.5 \mathrm{~mm}$ \\
\hline Active length & $150 \mathrm{~mm}$ \\
\hline & \\
\hline Stator rated line voltage (Y connexion) & $400 \mathrm{~V}$ \\
\hline Suply frequency & $50 \mathrm{~Hz}$ \\
\hline Pole pairs $p$ & 4 \\
\hline Active length & $150 \mathrm{~mm}$ \\
\hline Stator outer radius & $61 \mathrm{~mm}$ \\
\hline Airgap & $0.3 \mathrm{~mm}$ \\
\hline Number of stator slots & 24 \\
\hline Number of rotor slots & 48 \\
\hline Stator turns per phase & 296 \\
\hline Rotor turns per phase & 160 \\
\hline &
\end{tabular}

The convection heat transfer concerns the air-gaps, the external surface of MaGIM and the inner hole of the stator. The heat transfer coefficients are computed using well known formulae [13], [14], [15]. The stator is mainly cooled through the inner hole in which a fan blows an air flow. Table 2 gives the values of the different thermal coefficients used in the thermal model.

The convectionl coefficient $h_{\text {hole }}$ of the inner stator hole is calculated by:

$$
h_{\text {hole }}=\frac{N u_{i s} \cdot k}{R_{i s}}
$$

Where $R_{\text {is }}$ represent the inner stator radius and $k_{\text {air }}$ the thermal conductivity of air. $\mathrm{Nu}_{\text {is }}$ represents the Nusselt coefficient whose value for an internal forced convection is related to the Reynolds Re and Prandtl Pr numbers by:

$$
N u_{i s}=A \cdot R e^{n} \cdot \operatorname{Pr}^{m}
$$

The values of $\mathrm{A}, \mathrm{n}$ and $\mathrm{m}$ are given by:

$$
\begin{cases}A=3.66, n=0, m=0 & \text { if } R e<2000 \\ A=0.023, n=0.8, m=0.33 & \text { if } R e>2000\end{cases}
$$

The convection coefficients for the three airgap regions (IM, low and high speed gear sides) are expressed by:

$$
h_{\text {gap }}=\frac{N u_{g} \cdot k_{a i r}}{e_{g a p}}
$$

Where $h_{\text {gap }}$ is the convection coefficient of the considered airgap region and $\mathrm{e}_{\text {gap }}$ the airgap thickness.
The Nusselt number $\mathrm{Nu}_{\mathrm{g}}$ is related to Taylor number Ta by:

$$
\begin{cases}N u=2.2 & \text { if } T a<41 \\ N u=1.116 . \mathrm{Ta}^{0.63} \cdot \operatorname{Pr}^{0.27} & \text { if } \mathrm{Ta}>41\end{cases}
$$

Figure 2 shows the thermal network of MaGIM which consists of 15 nodes. The active parts are numbered as follows:

1(stator back-iron), 3(stator slot), 4(stator tooth), 7(highspeed rotor slot), 8(high-speed rotor tooth), 10(high-speed rotor back-iron), 11(high-speed rotor PMs), 14(stationary armature PMs), 15(stationary armature back-iron).

The heat sources (Joule and iron losses) are injected to these active nodes. They are obtained from the electromagnetic model presented above. Note that the low speed rotor pole-pieces are made from SMC materials whose losses are neglected. The pole-pieces are inserted in a fiber glass container to form the low-speed rotor. In this way, a sufficient structural strength to transmit the torque is ensured.

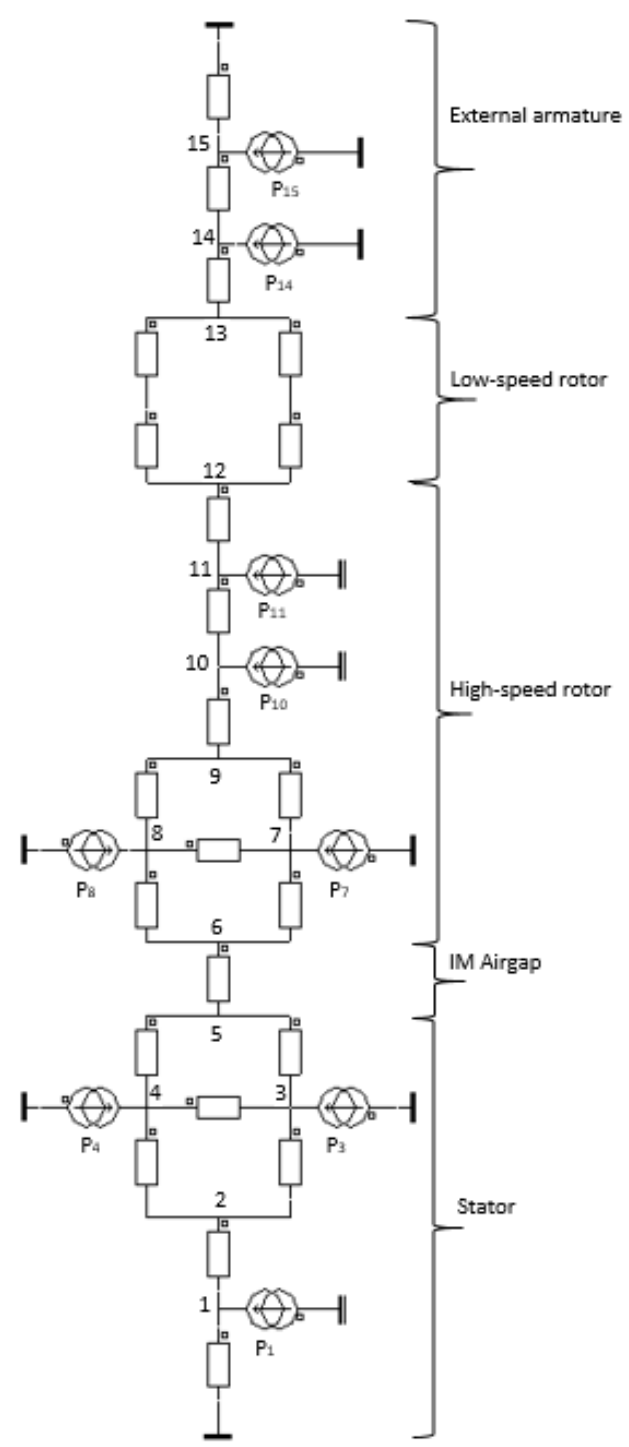

Fig. 2. Equivalent thermal network of MaGIM 
TABLE 2

THERMAL COEFFICIENTS USED IN THE THERMAL NETWORK

\begin{tabular}{l|c}
\hline \multicolumn{1}{c|}{ Region } & $\begin{array}{c}\text { Convection } \\
\text { coefficient }\left[\mathbf{W} / \mathbf{m}^{2}{ }^{\circ}{ }^{\circ} \mathbf{C}\right]\end{array}$ \\
\hline Inner stator hole & 98.7 \\
\hline Airgap (IM side) & 220 \\
\hline Airgap (high-speed rotor gear side) & 33 \\
\hline Airgap (stationary armature gear side) & 33 \\
\hline External surface of fixed armature & 50 \\
\hline \multicolumn{1}{c}{ Region } & Thermal conductivity \\
\hline Iron laminations & 28 \\
\hline Slot winding & 1 \\
\hline NdFeB PMs & 8.5 \\
\hline SMC pole-pieces & 2.2 \\
\hline fiberglass & 0.02 \\
\hline
\end{tabular}

\section{RESULTS AND DISCUSSION}

\section{A. Electromagnetic performances}

As stated above, a per-phase equivalent circuit is used to compute the performances of the induction motor. Table 3 gives the values of the electrical parameters of the machine. Note that the 2D FE model ignores the end-winding leakage inductances. Usual formulae [10] are used to compute these inductances and their values added to the ones computed in 2D. To get more precise results, a time-harmonic (TH) nonlinear (NL) 2D FE simulation with circuit coupling has been performed. The B-H curve of M400-50A laminations is used for the ferromagnetic parts.

For slip values up to 0.1 , Fig. 3 shows the torque vs. slip curves computed by the two models. The agreement is very good, the relative difference doesn't exceed $2 \%$. The rated torque of $14 \mathrm{Nm}$ is reached for a slip value of 0.08 .

Fig. 4 shows the stator current vs. slip curves obtained using the two models. The results issued from the equivalent circuit underestimate the no-load current. The relative difference is about $8 \%$ for $\mathrm{s}=0$. For higher slip values ( $\mathrm{s}>$ 0.04 ), the agreement is good as the relative difference doesn't exceed $3 \%$. The rated current obtained at a slip of 0.08 is about $3.1 \mathrm{~A}$.

Fig. 5 shows the power factor vs. slip curves obtained using the two models. Again, the agreement is very good as the relative difference doesn't exceed 3\%. The rated PF is around 0.58 which is relatively low. However, this represents usual FP values for small power induction motors with high pole numbers.

Fig. 6 shows the static torque vs. position of the lowspeed rotor; the high-speed rotor being held stationary. Both 2D and 3D FE computations are performed. The torque curve is almost sinusoidal and ripple free. The $2 \mathrm{D}$ pull-out torque is about $350 \mathrm{Nm}$ while the 3D model gives $310 \mathrm{Nm}$.

Hence, to obtain the right torque value while still using a $2 \mathrm{D}$ model, we simply multiply the $2 \mathrm{D}$ torque by a correction factor of about 0.88 (ratio of the 3D and 2D pull-out torques).
EQUIVALENT CIRCUIT PARAMETERS OF THE INDUCTION MOTOR

\begin{tabular}{l|l}
\hline \multicolumn{1}{c|}{ Electrical parameter } & \multicolumn{1}{c}{ Value } \\
\hline Stator inductance Ls & $0.276[\mathrm{H}]$ \\
\hline Rotor inductance Lr & $0.065[\mathrm{H}]$ \\
\hline Mutual inductance M & $0.121[\mathrm{H}]$ \\
\hline Stator resistance Rs & $6.3[\Omega]$ \\
\hline Rotor resistance Rr & $2.06[\Omega]$ \\
\hline
\end{tabular}

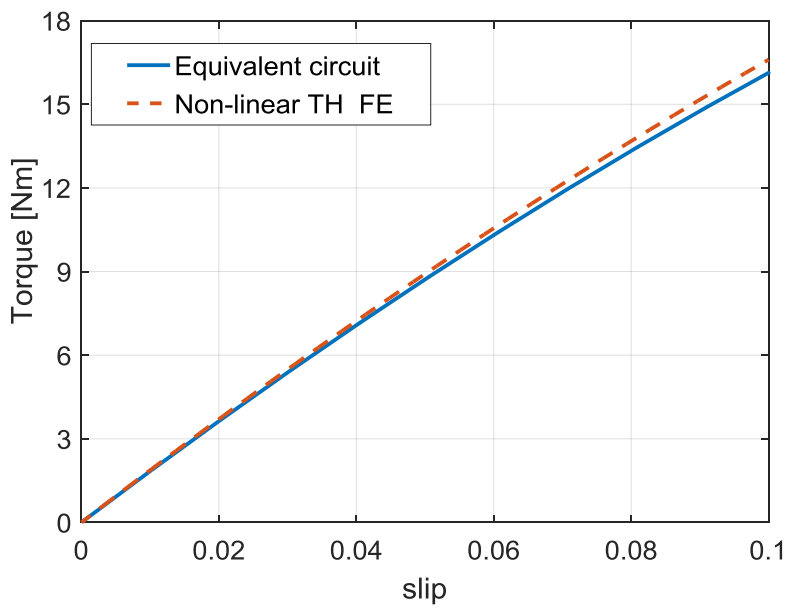

Fig. 3. Electromagnetic torque vs. slip curves

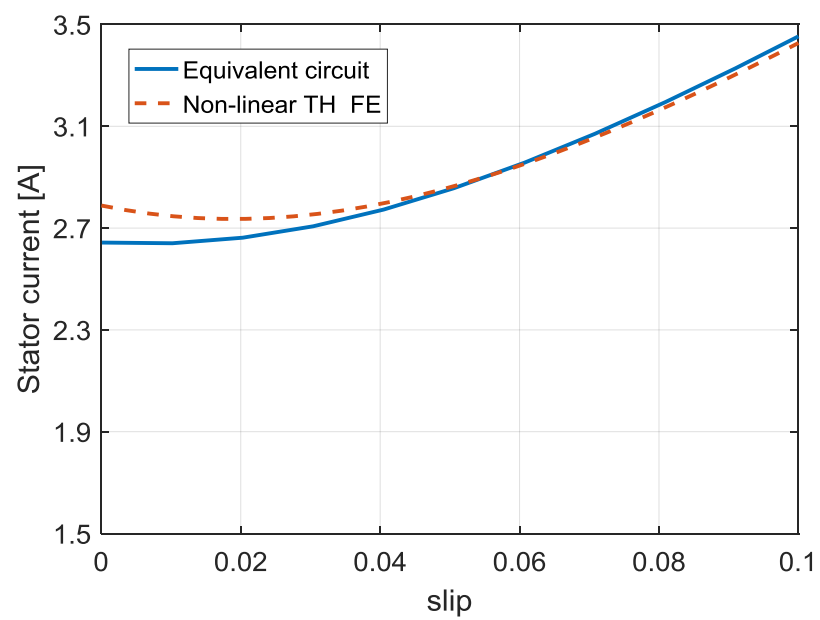

Fig. 4. Stator current vs. slip curves

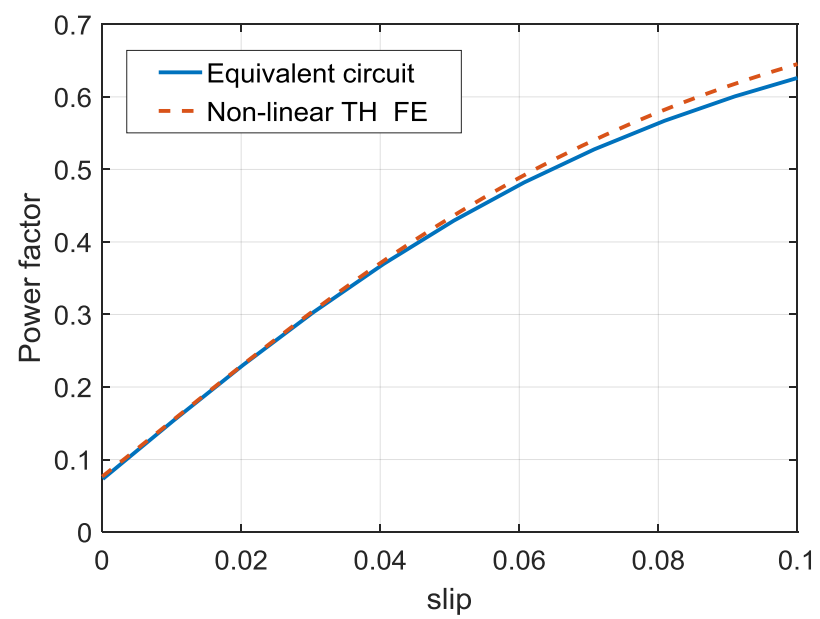

Fig. 5. Power factor vs. slip curves 


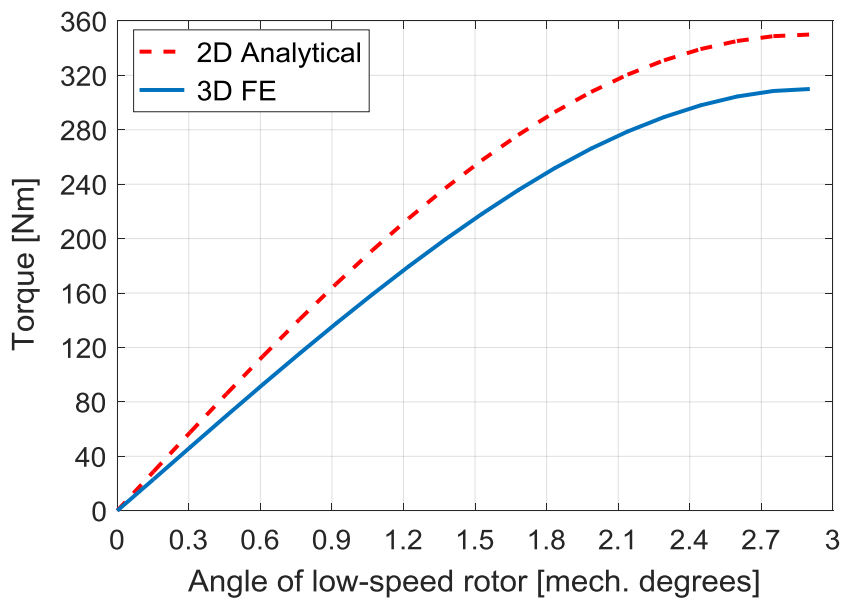

Fig. 6. Static torque vs. angular position of the low-speed rotor

For the rated operating conditions at constant speeds (45 $\mathrm{rpm}$ for the low-speed rotor and $680 \mathrm{rpm}$ for the high-speed rotor), a non-linear time-stepping 2D FE simulation with movement consideration and circuit coupling has been performed for the whole system. The relative positions between the high and the low speed rotors is set to get a corrected 2D torque value of $212 \mathrm{Nm}$ on the low speed rotor.

Fig. 7 shows the dynamic torque waveform of the low speed rotor. This torque is practically ripple free with a mean value of $212 \mathrm{Nm}$; the torque ripples don't exceed $1 \%$.

Fig. 8 presents the total torque exerted on the high-speed rotor. Of course, the mean torque is equal to zero since the gear and the machine develop opposite torques whose mean values are about $14 \mathrm{Nm}$. However, one can observe the torque ripples due to the machine and gear sides, these ripples represent $26 \%$ of the rated torque of $14 \mathrm{Nm}$. This is one of the great advantages of the magnetic gear which can transmit a free-ripple torque to the load (low speed) while the input torque (high speed) contains high pulsations.

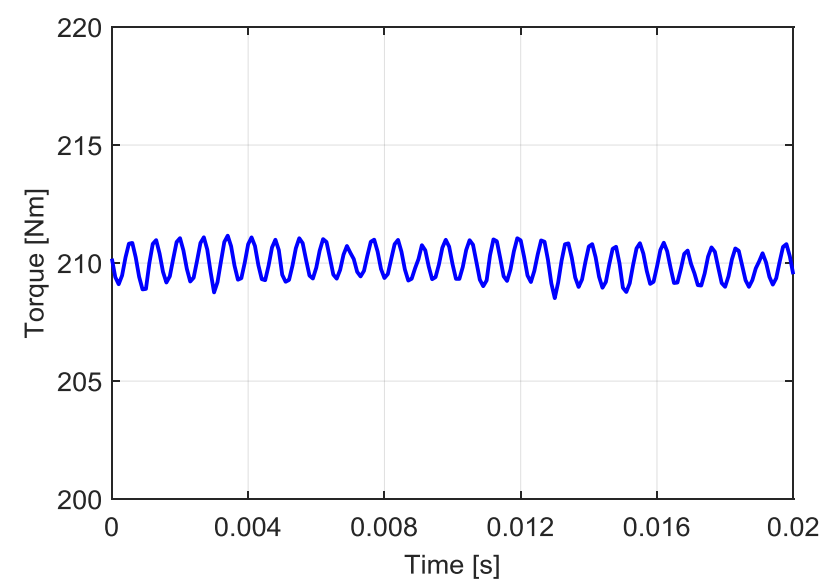

Fig. 7. Low-speed rotor dynamic torque at rated operation

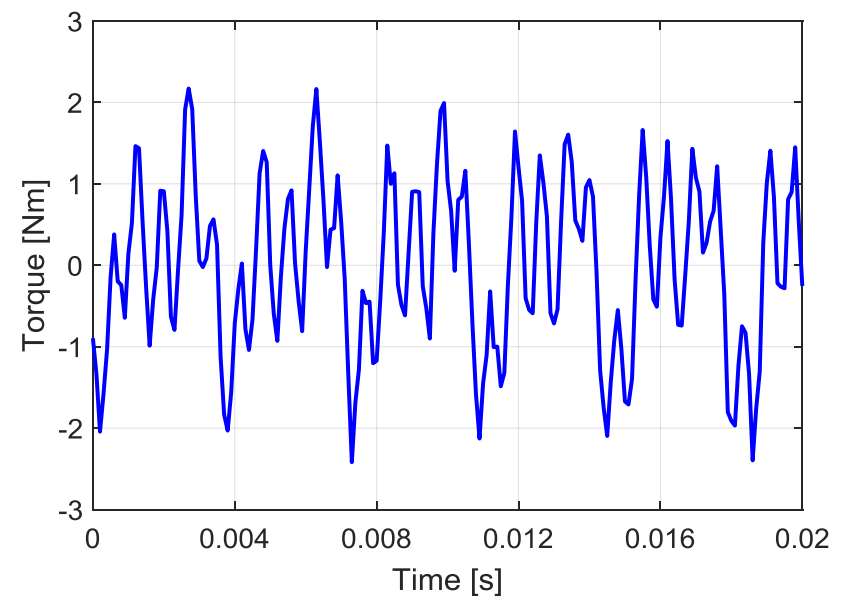

Fig. 8. High-speed rotor dynamic torque at rated operation

The active torque density at rated operation of MaGIM is about $26 \mathrm{Nm} / \mathrm{L}$. A mechanical gear with the same gear ratio exhibits a torque density of about $15 \mathrm{Nm} / \mathrm{L}$ [11]. When associated to a high-speed induction motor having a standard torque density of $10 \mathrm{Nm} / \mathrm{L}$, the overall system (IM + mechanical gear) will exhibit a torque density of $14 \mathrm{Nm} / \mathrm{L}$. This clearly shows that MaGIM is superior to the conventional system with the benefit of better reliability and low maintenance requirements.

\section{B. Performances of the thermal model}

The steady state temperature distribution in the active parts of the machine are computed for rated load conditions. The different losses computed by the electromagnetic model are given in Table 4. Notice that the iron losses are evaluated by the standard formulae [10]. Furthermore, the losses in the gear side (magnets and back-iron) are very low for the studied MaGIM so their values are set to zero for the thermal computation.

Table 5 gives the computed temperatures in the different regions of the device. As expected, the stator slots reach the highest temperature of $107^{\circ} \mathrm{C}$. The high-speed rotor temperatures vary between 91 and $98^{\circ} \mathrm{C}$, the lowest one concerns the PMs whose temperature reaches $91^{\circ} \mathrm{C}$.

The low speed rotor and the external armature temperatures are about $78^{\circ} \mathrm{C}$ and $66^{\circ} \mathrm{C}$ respectively because the large air-gaps on the gear sides act as a heat flux barrier. It is important to give a special care the high-speed rotor PMs as a high operating temperature could result in demagnetization problems. Hence, it is probably safer to use SmCo magnets on the high-speed rotor although they are more expensive than $\mathrm{NdFeB} \mathrm{PMs.}$

Nevertheless, the simplified 2D thermal model ignores the axial heat transfer, so the computed temperatures are probably higher compared the ones we would obtain if the axial heat transfer is considered. 
TABLE 4

DIFFERENT LOSSES IN MAGIM AT RATED OPERATION

\begin{tabular}{l|c}
\multicolumn{1}{c|}{ Region name } & Losses [W] \\
\hline Stator back-iron (node 1) & 18 \\
\hline Stator tooth (node 4) & 32 \\
\hline Stator slots Joule losses (node 3) & 194 \\
\hline Rotor slots Joule losses (node 7) & 131 \\
\hline
\end{tabular}

TABLE 5

TEMPERATURE DISTRIBUTION IN MAGIM AT RATED OPERATION

\begin{tabular}{l|c}
\hline \multicolumn{1}{c|}{ Region name } & Temperature, $\mathbf{T}\left[{ }^{\circ} \mathbf{C}\right]$ \\
\hline Stator slots (node 3) & 106.92 \\
\hline Stator teeth (node 4) & 96.94 \\
\hline Stator back- iron (node 1) & 93.85 \\
\hline High-speed rotor slots (node 7) & 98.36 \\
\hline High-speed rotor teeth (node 8) & 92.98 \\
\hline High-speed rotor back-iron (node 10) & 91.67 \\
\hline High-speed rotor PMs (node 11) & 91.58 \\
\hline Low-speed rotor (node 12) & 78.01 \\
\hline Fixed armature PMs (node 14) & 65.81 \\
\hline
\end{tabular}

\section{CONCLUSION}

In this paper, the sizing procedure of a magnetically geared induction machine MaGIM rated at $1 \mathrm{~kW}-45 \mathrm{rpm}$ has been presented. The device is intended for a constant speed operation on the $400 \mathrm{~V}-50 \mathrm{~Hz}$ network. Both electromagnetic and thermal analyses have been carried out by means of analytical and finite element computation tools.

We have shown that a compromise must be made to reach a compact magnetic gear while keeping acceptable energetic performances of the induction motor.

To estimate the temperature of MaGIM, we built a simplified lumped-parameter thermal model. The model was formulated from physical constants, heat transfer characteristics and dimensional data. It has been shown that the high-speed PMs can reach a relatively high temperature so the use of SmCo magnets would be preferable.

The designed MaGIM is currently under construction and we hope to publish the first experimental results in few months.

\section{REFERENCES}

[1] H.T.Faus, "Magnet gearing" U.S petent 2243555, May 27, 1941.

[2] K. Atallah and D. Howe, "A Novel High-Performance Magnetic Gear," IEEE Trans. Magn., Vol. 37, No. 4, pp. 2844-2846, Jul. 2001.

[3] S.Mezani, K, Atallah, and D.Howe, "A high-perfomance axial-field magnetic gear" J.Appl. Phys, Vol 99, pp 08R303-1-08R303-3,2006

[4] P. O. Rasmussen, T. O. Andersen, F. T. Jorgensen, and O. Nielsen, "Development of a high-performance magnetic gear," IEEE Trans. Ind. Appl., vol. 41, no. 3, pp. 764-770, May/Jun. 2005

[5] X. Li, K. T. Chau, M. Cheng, W. Hua, and Y. Du, "An improved coaxial magnetic gear using flux focusing," in Proc. ICEMS, Beijing, China, Aug. 2011, pp. 1-4.

[6] N. W. Frank and H. A. Toliyat, "Analysis of the concentric planetary magnetic gear with strengthened stator and interior permanent magnet inner rotor," IEEE Trans. Ind. Appl., vol. 47, no. 4, pp. 1652-1660, Jul./Aug. 2011.

[7] X. Liu, K. T. Chau, J. Z. Jiang, and C. Yu, "Design and analysis of interior magnet outer-rotor concentric magnetic gears," J. Appl. Phys., vol. 105, no. 7, pp. 07F101-1-07F101-3, Apr. 2009.
[8] S. Mezani, T. Hamiti, L. Belguerras, T. Lubin, M. Rashed and C. Gerada,"Magnetically Geared Induction Machines," IEEE Trans. Magn, vol. 51, no. 11, 8111404, Nov. 2015.

[9] Z. Q. Zhu, and D. Howe, "Influence of design parameters on cogging torque in permanent magnet machines," IEEE Trans. Ener. Conv., Vol. 15, No. 4, pp. 407-412, Dec. 2000.

[10] I. Boldea and S. A. Nasar, The Induction Machines Design Handbook, 2nd edition, CRC Press, 2009, 845 p.

[11] E. Gouda, S. Mezani, L. Baghli, and A. Rezzoug, "Comparative Study Between Mechanical and Magnetic Planetary Gears," IEEE Trans. Magn., Vol. 47, No. 2, pp. 439-450, Feb. 2011.

[12] T. Lubin, S. Mezani, and A. Rezzoug, "Analytical computation of the magnetic field distribution in a magnetic gear," IEEE Trans. Magn., vol. 46, no. 7, pp. 2611-2621, Jul. 2010.

[13] P. H. Mellor, D. Roberts, and D. R. Turner, "Lumped parameter thermal model for electrical machines of TEFC design," IEE Proceedings-B, Vol. 138, No. 5, pp. 205-218. Sept. 1991.

[14] G. Kylander, "Temperature simulation of a $15 \mathrm{~kW}$ induction machine operating at variable speed," Proceeding ICEM, Manchester (UK) Vol. 3, pp. 943-947, Sept. 1992.

[15] A.Boglietti, A. Cavagnino, and D. Staton, "Determination of Critical Parameters in Electrical Machine Thermal Models," IEEE Trans. Ind. Appl., Vol.. 44, no. 4, pp. 1150-1159, Jul./Aug. 2008.

\section{BIOGRAPHIES}

Badr-el-Boudour Bidouche received a master degree in electrical engineering in 2015 from the University of Sciences and Technology Houari Boumediene, Algiers, Algeria. She also received a research master degree in electrical energy in 2016 from the Graduate School of engineering Energy, Water and Environmental sciences of the Institut National Polytechnique de Grenoble, France. Currently, she is working on the design of a magnetically geared induction machine as a second year doctoral student, at the the "Groupe de Recherche en Energie Electrique de Nancy", GREEN of the Lorraine University, Nancy, France

Thierry Lubin received the M.S. degree in electrical engineering from the University Pierre et Marie Curie, Paris, France, in 1994, and the Ph.D. degree from the University of Lorraine, Nancy, France, in 2003. He is currently an Associate Professor of Electrical Engineering with the "Groupe de Recherche en Energie Electrique de Nancy", GREEN, Nancy, France. His research interests include analytical modeling, design, and control of electrical machines, and the use of superconductors in electromechanical devices.

Smail Mezani received the Dipl.-Ing. and Magister degrees in electrical engineering from the University of Sciences and Technology Houari Boumediene, Algiers, Algeria in 1996 and 1999, respectively, and the Ph.D. degree from the Institut National Polytechnique de Lorraine, Nancy, France, in 2004. He is a Lecturer of Electrical Engineering with the Faculty of Sciences and Technology, University of Lorraine, Nancy, where his research works are undertaken in the "Groupe de Recherche en Energie Electrique de Nancy". From November 2013 to May 2015 he was on secondment from the University of Lorraine, working at the Power Electronics, Machines, and Control (PEMC) Group, University of Nottingham, U.K., on magnetically geared induction machines in the frame of a Marie-Curie Intra European Fellowship. His research interests include numerical and analytical modeling of electrical machines, coupled magnetic and thermal problems, contactless torque transmissions by magnetic gears and couplers, and the use of superconductors in electromechanical devices. 